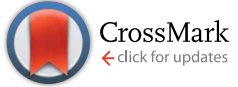

Cite this: RSC Adv., 2017, 7, 6981

Received 12th October 2016 Accepted 7th November 2016

DOI: $10.1039 / c 6 r a 25120 j$

www.rsc.org/advances

\section{Study on the curing reaction kinetics of a novel epoxy system}

\begin{abstract}
Jiheng Ding, ${ }^{* a}$ Wanjun Peng, ${ }^{\text {ab }}$ Ting Luo ${ }^{\text {ac }}$ and Haibin Yu*a
The anhydride curing agent of 3,6-enodro-1,2,3,6-tetrahydrophthalic anhydride (OBPA) and the reactive epoxy diluent of furfuryl glycidyl ether (FGE) were prepared and characterized by Fourier transform infrared spectroscopy (FTIR) and nuclear magnetic resonance $\left({ }^{1} \mathrm{H} N M R\right)$. The curing reaction kinetics process of an EP/OBPA/FGE epoxy system was studied by non-isothermal DSC methods. The parameters of the kinetics were calculated using the Kissinger model, Crnae model, Ozawa model and $\beta-T$ (temperature-heating speed) extrapolation, respectively. In addition, the effect of FGE on the thermomechanical properties (glass transition temperature) and mechanical properties (flexural strength and the tensile strength) in the EP/OBPA/FGE were studied, indicating that when the content of FGE was $10 \mathrm{wt} \%$ the epoxy system reaches the best mechanical properties.
\end{abstract}

\section{Introduction}

Epoxy resin has excellent mechanical properties, bonding properties, electrical insulation, strong mechanical properties, and a small curing shrinkage and other advantages in physical and chemical properties, which are widely used in the chemical industry, transportation, and aerospace fields. Bisphenol A epoxy resin is one of the most widely used epoxy resins, which accounts for about $80 \%$ of the whole epoxy resin system and is often used in the manufacture of industrial coatings, adhesives and electronic panels $e t \mathrm{c}^{1-5}$

Generally, the bisphenol A type epoxy resin possesses high viscosity, poor permeability and fluidity. In order to facilitate the process of operation, it usually need to add large amounts of volatile organic compounds (VOC) as its solvent or diluent for reducing the viscosity and improving the fluidity of the epoxy resin. Ethanol, acetone, toluene, xylene etc., are the most commonly used solvents for epoxy resin, however, most of them are flammable, toxic or difficult to clean, and may cause danger of explosion, what's more, the use of solvents not only caused a substantial loss of oil resources, but also caused serious environmental pollution for living. Therefore, it is very important to reduce the use of VOC whether in economic costs or in environmental responsibility. ${ }^{6-11}$

Reactive epoxy diluents is a kind of compound with low viscosity can dissolve or disperse into film material, reduce the

${ }^{a}$ Key Laboratory of Marine Materials and Related Technologies, Key Laboratory of Marine Materials and Protective Technologies of Zhejiang Province, Ningbo Institute of Materials Technology and Engineering, Chinese Academy of Sciences, Ningbo 315201, P. R. China.E-mail: dingjh@nimte.ac.cn; haibinyu@nimte.ac.cn

${ }^{b}$ College of Materials Science and Engineering, Hunan University, Changsha 410000, P. R. China

${ }^{c}$ College of Chemistry and Chemical Engineering, Hunan Normal University, Changsha 410081, P. R. China viscosity of epoxy resin, and can be involved in the process of resin curing reaction, forming the non-volatile component and stay in the curing system. It's well know that phenyl glycidyl ether, benzyl glycidyl ether, ortho methyl phenyl glycidyl ether, ethylene glycol diglycidyl ether, and butyl glycidyl ether are the commonly used for epoxy diluents, however, because of small molecules containing aromatic glycidyl ether has the potential carcinogenic effects, and the aliphatic glycidyl ether with shortcomings to reduce rigidity, heat resistance and mechanical strength for epoxy resin, which limited their application in epoxy systems. In view of the above results, the preparation of bio-based reactive epoxy diluents has gradually become a hot spot in the field of epoxy diluents. ${ }^{12,13} \mathrm{Hu}$ et al. synthesized the 1,4-bis[(2-oxiranylmethoxy)methyl]-furan (BOF), which is a promising to substitute the petroleum-based 1,4-bis[(2oxiranylmethoxy)methyl]-benzene (BOB) to bring about a vast improvement in the thermodynamic properties of thermosetting resin. ${ }^{14}$ Huang et al. reported that the bio-based maleopimarate as an epoxy curing agent to replace the petrochemical-based trimellitic anhydride..$^{15}$ Ma et al. synthesized a novel itaconic acid based glycidyl ether, which has great potential to replace the petroleum-based thermosetting glycidyl ether. ${ }^{16}$

Furfural is an important renewable material, which mainly exists in corncob, and as the main structure of the furan ring with high mechanical rigidity can be comparable with the petroleum based aromatic ring and fatty ring. So the furfural and its derivatives such as furfuryl alcohol, furan and furoic acid are widely used in the polymer domain. Furfuryl glycidyl ether (FGE Fig. 1a) is obtained by reaction from furfuryl alcohol and epichlorohydrin, where the epichlorohydrin is the derivatives of glycerol, and furfuryl alcohol is from furfural, so FGE is a kind of bio-based epoxy monomer. There is the conjugated 


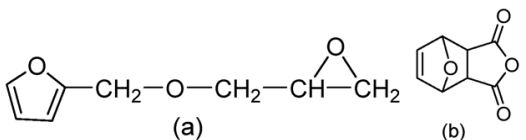

(a)

Table 1 The synthetic route of OBPA and FGE

FGE

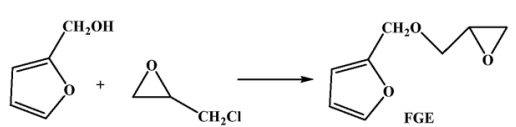

Fig. 1 The structures of (a) FGE and (b) OBPA.

ring in the molecular structure of FGE, which has high flexibility, while not losing rigidity. The structure of FGE can not only solve the problem of rigidity and heat resistance of aliphatic epoxy diluent, and can improve the brittleness and poor impact resistance of the aromatic epoxy diluent epoxy curing system. Therefore, as a new type of epoxy reactive diluent, FGE is expected to replace the traditional aryl ring, such as phenyl ether or benzyl ether. ${ }^{17,18}$

On the other hand, the compound of 3,6-oxygen bridge1,2,3,6-four hydrogen phthalic anhydride (OBPA, Fig. 1b) come from the adducts of D-A reaction of furan and maleic anhydride, and its molecular structure contains benzene and furan ring with outstanding rigidity, therefore, it is expected to replace the traditional epoxy curing agent such as phthalic anhydride or trimellitic anhydride become a renewable biobased epoxy curing agent. ${ }^{19-25}$

In order to get rid of the use of VOC in epoxy resin system, we have done the following research: (1) compounds FGE and OBPA were synthesized and were used as curing agent and reactive diluent of epoxy resin, respectively. Here, we hoped that the synthesized FGE could play dual roles in the epoxy composites, namely it can not only be used as a solvent for dissolve OBPA, but also as a diluent for epoxy resin. (2) The EP/ OBPA/FGE curing system was prepared and its thermal and kinetic parameters of curing process was analyzed and calculated by the non-isothermal DSC method, and the optimum curing temperature of the system was determined by $T$ $\beta$ extrapolation. What's more, the mechanical proprieties of EP/ OBPA/FGE were studied too. Up to now, the bio-based diluent of FGE and curing agent of OBPA for epoxy resin has never been reported.

\section{Experimental}

\section{Materials}

Furan, maleic anhydride, epichlorohydrin, and 1-methyl imidazole were purchased from Aladdin Industrial Corporation, and were used without further purification. Deionized water was used throughout the experiments. Furfuryl alcohol (FA), provided by Hubei new materials Co. Ltd. Bisphenol A epoxy resin (EP), industrial grade (E-44, the epoxy value is 0.46), provided by Zhejiang Anbang coating Co. Ltd.; All other reagents were purchased from Aladdin and used as received.

\section{Synthesis of FGE}

The FGE was synthesized through the route in the Table 1. Epichlorohydrin $(117.5 \mathrm{~g}, 1.31 \mathrm{~mol})$ and tetrabutylammonium hydrogen sulfate $(4.11 \mathrm{~g}, 3.5 \%)$ were added into a $500 \mathrm{~mL}$ threenecked round-bottom flask. The system temperature was kept

OBPA

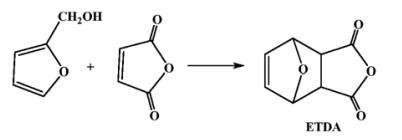

in an ice-water bath at $0{ }^{\circ} \mathrm{C}$. the furfuryl alcohol $(63 \mathrm{~g}, 0.64 \mathrm{~mol})$ was dropped into above the solution over a period of $30 \mathrm{~min}$. Then $\mathrm{NaOH}$ aqueous $(140 \mathrm{~mL}, 50 \mathrm{wt} \%)$ was added into the mixture over a period of $60 \mathrm{~min}$ and controlled the system temperature was not more than $10^{\circ} \mathrm{C}$. After $3.5 \mathrm{~h}$, crude product was washed by water three times, and the organic layer was collected and dried by magnesium sulfate anhydrous for $24 \mathrm{~h}$, and the solvent was removed using by a rotary evaporator. The refined product was obtained by chromatography on a silica gel column with mixed solvent of ethyl acetate/hexane $(5: 1)$. Yield: $\sim 82 \%$.

FA- ${ }^{1}$ H NMR (400 MHz, d6-DMSO): ( $\delta$, ppm) 7.37 (d, 1H), 6.31 (d, 1H), $6.25(\mathrm{t}, 1 \mathrm{H}), 4.25(\mathrm{~s}, 2 \mathrm{H})$; FGE- ${ }^{1} \mathrm{H}$ NMR $(400 \mathrm{MHz}$, d6$\left.\mathrm{DCl}_{3}\right):(\delta, \mathrm{ppm}) 7.43(\mathrm{q}, 1 \mathrm{H}), 6.35(\mathrm{~d}, 1 \mathrm{H}), 6.39(\mathrm{t}, 1 \mathrm{H}), 4.55(\mathrm{~s}$, $2 \mathrm{H}), 3.76(\mathrm{q}, 1 \mathrm{H}), 3.45(\mathrm{q}, 2 \mathrm{H}), 2.81(\mathrm{q}, 1 \mathrm{H}), 2.62$ (quint, $2 \mathrm{H}), 2.59$ (q, 1H);

\section{Synthesis of D-A adduct of OBPA}

The OBPA was prepared according to the Diels-Alder reaction in the Table 1 . Maleic anhydride $(20 \mathrm{~g}, 0.20 \mathrm{~mol})$ was dissolved in ether $(150 \mathrm{~mL})$ at room temperature; furan $(15 \mathrm{~mL}, 0.20 \mathrm{~mol})$ was dropped into the above-mentioned solution for $6 \mathrm{~h}$ under magnetic stirring. And then the product was filtered to collect the OBPA. The filter cake washed with a small amount of ethanol three times and dried at $40{ }^{\circ} \mathrm{C}$ in a vacuum until constant weight. Yield: $\sim 98 \%$.

OBPA $-{ }^{1} \mathrm{H}$ NMR $\left(400 \mathrm{MHz}, \mathrm{d} 6-\mathrm{DCl}_{3}\right):(\delta, \mathrm{ppm}) 6.58(\mathrm{q}, 2 \mathrm{H})$, $5.35(\mathrm{q}, 2 \mathrm{H}), 3.31(\mathrm{~s}, 2 \mathrm{H})$.

\section{Prepared of EP/OBPA/FGE polymer system}

Most of the anhydride is solid, and it is needed to be mixed with the resin in the appropriate temperature to overcome this limitation. In this paper, we used FGE as a solvent for anhydride curing agents. Firstly, OBPA (10 g) was dissolved in ( $3 \mathrm{~g})$ of FGE at room temperature for 10 min without any solvent. Then, the above-mentioned solution and $0.33 \mathrm{~g}$ of curing accelerators of 1methyl imidazole were added in $20 \mathrm{~g}$ of epoxy resin at room temperature for $5 \mathrm{~min}$. The resultant homogeneous mixture was degassed, and is added to the aluminium crucible $(\sim 3 \mathrm{mg})$, the DSC scans were performed according to the setting of the heating rate, and the DSC curves were recorded.

\section{Preparation of cured EP/OBPA/FGE polymer}

The epoxy anhydride curing agent OBPA (10 g) and curing accelerators of 1-methyl imidazole $(0.33 \mathrm{~g})$ were dissolved into 
a certain amount of FGE, the mixture was added into EP (20 g) and heated to $80{ }^{\circ} \mathrm{C}$ for $30 \mathrm{~min}$ under vacuum. The resultant homogeneous compound was degassed, poured into a closed silicone rubber mould and cured at the given temperature. The curing temperature was selected based on the optimum temperature from above the dynamic test results.

\section{Characterizations}

The chemical structures of products were confirmed by FTIR and ${ }^{1} \mathrm{H}-\mathrm{NMR}$ spectras. The FTIR spectrum $(\mathrm{KBr})$ was collected with a Thermo Nicolet Nexus 6700 instrument. ${ }^{1} \mathrm{H}-\mathrm{NMR}$ spectra was obtained at room temperature on a $400 \mathrm{MHz}$ AVANCE III NMR spectrometer in DMSO and $\mathrm{CDCl}_{3}$ with tetramethylsilane as internal reference. The DSC curves were obtained using a NETZSCH DSC 214 instrument with the protection of nitrogen and the flow rate was about $20 \mathrm{~mL} \min ^{-1}$. The scanning temperature of system was set from 25 to $300{ }^{\circ} \mathrm{C}$ and the heating rates were set to $\beta=5,10,15,20,25 \mathrm{~K} \mathrm{~min}^{-1}$. The glass transition temperature $\left(T_{\mathrm{g}}\right)$ was measured by the NETZSCH DSC 214 instrument under nitrogen atmosphere with the heating rate of $20{ }^{\circ} \mathrm{C} \mathrm{min}{ }^{-1}$, the heating temperature range from 25 to $200{ }^{\circ} \mathrm{C}$. Bending and tensile properties of samples were tested by the WDW-05 electronic universal testing machine and the standards as follows: the bending performances were tested according to the GB/T 2570-1995, the tensile properties were tested following GB/T 2568-1995, the test results to take the average of six samples.

\section{Results and discussion}

\section{Synthesis and characterization of FGE}

In this work, FGE was prepared according to one-step method from epichlorohydrin and furfuryl alcohol, and the purity of FGE was up to $99.7 \%$. The chemical structure of FGE was firm by FTIR and ${ }^{1} \mathrm{H}$-NMR.

Fig. 2 shows the FTIR spectra of FGE. For FA, the peaks at 3150 and $3110 \mathrm{~cm}^{-1}$ belong to the stretching vibrations of $\mathrm{C}-\mathrm{H}$ in furan ring; the peak at $1508 \mathrm{~cm}^{-1}$ belong to stretching vibration of $\mathrm{C}-\mathrm{C}$ in furan ring; the peaks at $1100 \mathrm{~cm}^{-1}, 1015$ $\mathrm{cm}^{-1}$, and $755 \mathrm{~cm}^{-1}$ are the stretching vibrations of $\mathrm{C}-\mathrm{O}$, furan

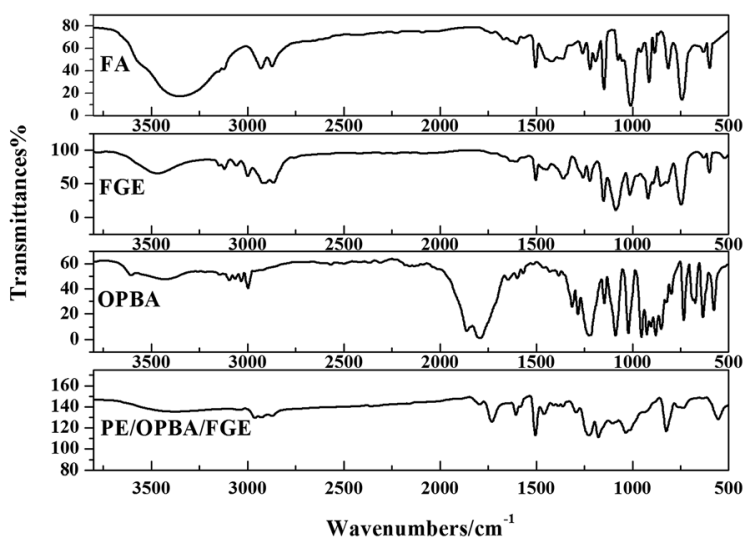

Fig. 2 The FTIR spectra of FA, FGE, ETA, and EP/OBPA/FGE. ring breathing and monosubstituted furan ring, respectively. Compared to FA, the new peaks at $3060 \mathrm{~cm}^{-1}, 1259 \mathrm{~cm}^{-1}, 858$ $\mathrm{cm}^{-1}$, and $914 \mathrm{~cm}^{-1}$ are assigned to stretching vibrations of $\mathrm{C}-\mathrm{H}$ and $\mathrm{C}-\mathrm{O}-\mathrm{C}$ in oxirane ring for FGE. The peaks at $3400 \mathrm{~cm}^{-1}$ and $3465 \mathrm{~cm}^{-1}$ are ascribed to $\mathrm{O}-\mathrm{H}$ of FA and FGE. The FTIR results proved that the product of FGE possesses both furan and oxirane rings, which is also the chemical structure of the target material FGE.

The ${ }^{1} \mathrm{H}-\mathrm{NMR}$ characteristic peaks of the FGE was listed in Fig. 3(1). The signals from 2.65 to $2.75 \mathrm{ppm}$ were assigned to the protons in the oxirane ring (designated as protons 7 ), while those signals at 3.42-3.85 ppm were assigned to protons 5 of $-\mathrm{CH}_{2}$ in the oxirane ring. The signal at $3.22 \mathrm{ppm}$ was assigned to proto 6 of $-\mathrm{CH}$ adjacent to the oxirane ring. The signals at 6.26.3 and $7.4 \mathrm{ppm}$ corresponding to protons 2,3 and 1 in furan ring, respectively. In addition, the signal at $4.5 \mathrm{ppm}$ was assigned to proto of $-\mathrm{OCH}_{2}$ in furan ring and it indicted that the protons 4 link the glycidyl ether moiety to the furan ring. The signal at $7.28 \mathrm{ppm}$ was assigned water peak in the $\mathrm{CDCl}_{3}$ solvent.

\section{Synthesis and characterization of OBPA}

The FTIR spectrum of OBPA was shown in Fig. 2 too. The peaks at 3150 and $3110 \mathrm{~cm}^{-1}$ belong to the stretching vibrations of $\mathrm{C}-\mathrm{H}$ in furan ring; and the peak at $1640 \mathrm{~cm}^{-1}$ belong to stretching vibration of $\mathrm{C}=\mathrm{C}$ in furan ring; the peak at $1725 \mathrm{~cm}^{-1}$ belong to stretching vibration of COOCO in OBPA.

The ${ }^{1} \mathrm{H}-\mathrm{NMR}$ characteristic peaks of the OBPA were shown in Fig. 3(2). The signals from 3.25 to $3.65 \mathrm{ppm}$ were assigned to the protons 4 and 5 of $-\mathrm{CH}$; those signals at $5.85 \mathrm{ppm}$ were assigned to protons 3 and 6 of $-\mathrm{CH}$ in the epoxy ring; and the signal at $6.32 \mathrm{ppm}$ was assigned to protons 1 and 2 of $\mathrm{C}=\mathrm{C}$ adjacent to the furan ring. The signal at $2.52 \mathrm{ppm}$ was assigned water peak in the DMSO solvent.

The FTIR and ${ }^{1} \mathrm{H}-\mathrm{NMR}$ results proved that the chemical structure of the target material OBPA.

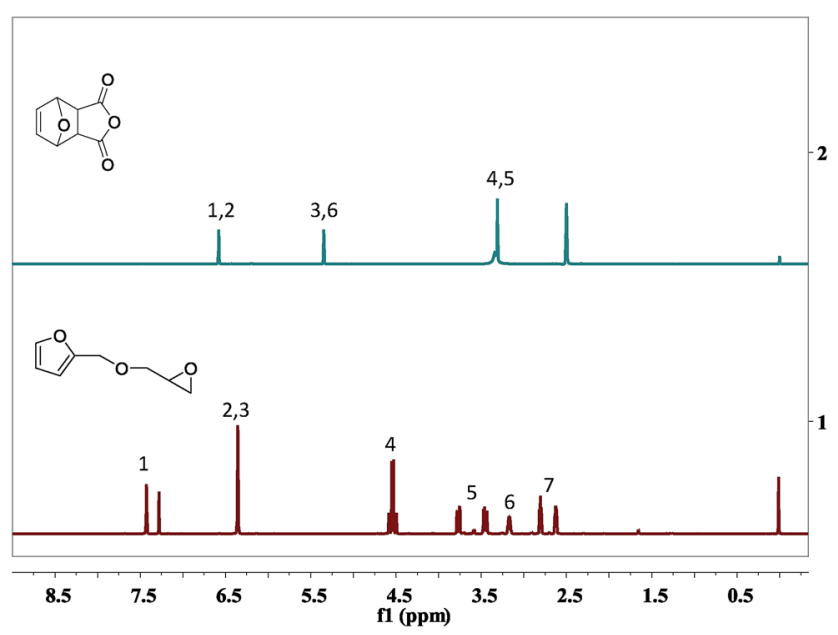

Fig. 3 Proton-NMR spectrums for the FA, FGE and OBPA. 


\section{Prepared and characterization of EP/OBPA/FGE}

From the Fig. 2, the peak of COOCO at $1725 \mathrm{~cm}^{-1}$ disappeared and a new peak at $1775 \mathrm{~cm}^{-1}$ belonging to the stretching vibrations of $\mathrm{C}=\mathrm{O}$ was observed in EP/OBPA/FGE. The peak at $1640 \mathrm{~cm}^{-1}$ belongs to stretching vibration of $\mathrm{C}=\mathrm{C}$ in furan ring. Moreover, the signals of epoxy group at $914 \mathrm{~cm}^{-1}$ and $\mathrm{O}-\mathrm{H}$ at $3450 \mathrm{~cm}^{-1}$ in EP and FGE disappeared. Those results demonstrated that the reaction of EP, OBPA, and FGE was completed.

\section{The DSC characterization of EP/OBPA/FGE}

Fig. 4 shows the non-isothermal DSC curves of EP/OBPA/FGE polymer system, and the kinetic parameters of the curing process including the heating rate $(\beta)$, the starting temperature $\left(T_{\mathrm{i}}\right)$, the peak temperature $\left(T_{\mathrm{p}}\right)$, and the peak end temperature $\left(T_{\mathrm{f}}\right)$ were recorded and listed in Table 2.

According to the chart, during the curing process of the nonisothermal of EP/OBPA/FGE system, the characteristic temperature of $T_{\mathrm{i}}, T_{\mathrm{p}}$, and $T_{\mathrm{f}}$ increased with the increase of heating rate, and the exothermic peaks of curing reaction gradually became sharp, and moved towards the direction of high temperature. According to the analysis results, on the other hand, during the curing process of EP/OBPA/FGE system, the thermal inertia and heat flux increased with the increase of heating rate, and the difference in temperature caused by the thermal effect became larger, so the curing exothermic peak shifted to high temperature. What's more, when the heating rate of the system was low, the system has sufficient time to react, so the curing reaction of the system could also be occurred at low temperature. In addition, the values of $\Delta H$ of the system gradually became smaller with the increase of heating rate, indicting that the lower of the value of heating rate, the more complete of the curing reaction of the system.

\section{The kinetic parameters of EP/OBPA/FGE system}

The analysis and calculation of the curing reaction kinetic parameters of EP/OBPA/FGE polymer system have important theoretical and practical significance for its application in industrial. The value of apparent activation energy $\left(E_{\mathrm{a}}\right)$ can directly reflect the degree of difficulty in the curing reaction of the system. And the reaction can occur only when the energy of

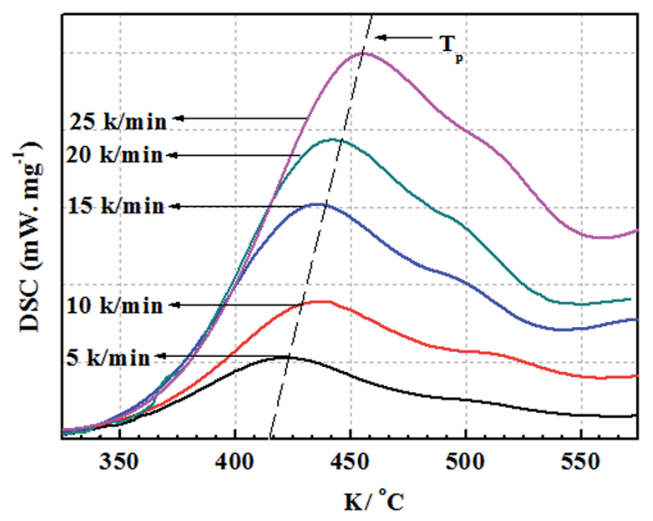

Fig. 4 Non-isothermal DSC curves of EP/OBPA/FGE system.
Table 2 Characteristic temperature from DSC curves

\begin{tabular}{llll}
\hline$\beta /\left(\mathrm{K} \mathrm{min}^{-1}\right)$ & $T_{\mathrm{i}} / \mathrm{K}$ & $T_{\mathrm{p}} / \mathrm{K}$ & $T_{\mathrm{f}} / \mathrm{K}$ \\
\hline 5 & 345.15 & 419.15 & 488.15 \\
10 & 348.15 & 433.15 & 493.15 \\
15 & 354.15 & 439.15 & 515.15 \\
20 & 360.15 & 445.15 & 530.15 \\
25 & 372.15 & 450.15 & 551.15 \\
\hline
\end{tabular}

$\mathrm{EP} / \mathrm{OBPA} / \mathrm{FGE}$ polymer system is greater than $E_{\text {a }}$, otherwise the curing reaction will not be occurred. In addition, the parameter of reaction series $n$ is usually used to measure the degree of complexity of the system curing reaction, and the curing kinetic equation for EP/OBPA/FGE system can be calculated according to the value of $n$. In this study, the Kissinger, Owaza and Crnae equations were used to obtain the linear relation diagrams of $\ln \left(\beta / T_{\mathrm{p}}{ }^{2}\right)$ and $\ln \beta$ to $1 / T_{\mathrm{p}}$, and then the curves were processed by linear fitting method. Finally, the values of the apparent activation energy $E_{\mathrm{a}}$, the pre-exponential factor $A$ and the reaction order $n$ of the system were obtained through above the analysis and calculation.

The curing kinetics models of epoxy system mainly including Kissinger, Fly-Wall-Ozawa and Friedman-Reich-Levi equations, and the Kissinger and Fly-Wall-Ozawa equations are the most commonly used for kinetics, and they follow the eqn (1). The Kissinger equation can be obtained by derivation and differential treatment to eqn (1), and the Kissinger equation was shown in eqn (2). Here, the value of $\ln [\mathrm{d} f(\alpha) / \mathrm{d}(\alpha)]$ is approximately 0 , as a consequence the eqn (2) can be further simplified to eqn (3).

$$
\begin{gathered}
\frac{\mathrm{d} \alpha}{\mathrm{d} t}=K(T)(1-\alpha)^{n} \\
\ln \left[\frac{\beta}{T_{\mathrm{p}}^{2}}\right]=\ln \left[\frac{A R}{E_{\mathrm{a}}}\right]+\ln -\left[\frac{\mathrm{d} f(\alpha)}{\mathrm{d}(\alpha)}\right]_{\alpha_{\mathrm{p}}}-\frac{E_{\mathrm{a}}}{R T_{\mathrm{p}}} \\
\ln \left(\frac{\beta}{T_{\mathrm{p}}{ }^{2}}\right)=\ln \left(\frac{A R}{E_{\mathrm{a}}}\right)-\left(\frac{E_{\mathrm{a}}}{R T_{\mathrm{p}}}\right)
\end{gathered}
$$

3

$$
A=\left[\beta E_{\mathrm{a}} \exp \left(E_{\mathrm{a}} / R T_{\mathrm{p}}\right)\right] / R T_{\mathrm{p}}^{2}
$$

where, the $t$ represents time, $\min ^{-1} ; R$ is the perfect gas constant, and the value of $8.32144 \mathrm{~J}(\mathrm{~mol} \mathrm{~K})^{-1} ; E_{\mathrm{a}}$ is the apparent activation energy, $\mathrm{J} \mathrm{mol}^{-1} ; A$ is the pre-exponential factor $\mathrm{min}^{-1}$; $\beta$ is the heating rate, $\mathrm{K} \mathrm{min}^{-1} ; T_{\mathrm{p}}$ is the peak temperature, $\mathrm{K}$.

The linear relationship of $\ln \left(\beta / T_{\mathrm{p}}{ }^{2}\right)$ and $1 / T_{\mathrm{p}}$ can be obtained through the eqn (3), and the curve was shown in Fig. 5A. The values of slope and intercept of curve were obtained by linear fitting to the curve were -8703.74 and 10.30 , respectively. The results were calculated in the eqn (3), and the value of apparent activation energy $E_{\mathrm{a}}$ was $72.37 \mathrm{~kJ} \mathrm{~mol}^{-1}$. In addition, the eqn (3) was deformed into as the eqn (4), and the values of preexponential factor $A$ can be calculated and obtained via the 
eqn (4) based on the value of $E_{\mathrm{a}}$. The values of pre-exponential factor $A$ were listed in Table 3 and the average value of $A$ is $2.640 \times 10^{8} \mathrm{~min}^{-1}$.

According to the relevant researches, the reaction order $n$ of the EP/OBPA/FGE polymer system can be obtained by the calculation of the Crnae equation in eqn (5). Here, the value of $E_{\mathrm{a}} / n R$ is much larger than that of $2 T_{\mathrm{p}}$ in the Crnae equation, so the eqn (5) can be simplified into the form of eqn (6). The linear relationship of $\ln \beta$ and $1 / T_{\mathrm{p}}$ (Fig. 5B) can be gotten through the eqn (6), and the values of slope and reaction order $n$ were obtained by linear fitting to the curve, they were -9538.51 and 0.912 , respectively.

$$
\begin{gathered}
\frac{\mathrm{d} \ln \beta}{\mathrm{d}\left(1 / T_{\mathrm{p}}\right)}=-\left(E_{\mathrm{a}} / n R+2 T_{\mathrm{p}}\right) \\
\frac{\mathrm{d} \ln \beta}{\mathrm{d}\left(1 / T_{\mathrm{p}}\right)}=-\frac{E_{\mathrm{a}}}{n R}
\end{gathered}
$$

Generally, the kinetic parameters of EP/OBPA/FGE polymer system can also be solved by using the Ozawa model equation. And because the curing reaction mechanism was set up in advance for the Kissinger equation during calculation process, it tends to give the experimental data a greater error, and the error can be avoided by the Ozawa model. Therefore, the Ozawa equation is often used to verify the value of apparent activation energy $E_{\mathrm{a}}$ obtained by the Kissinger model. The Ozawa model is as follows:

$$
\lg \beta=\lg \left[\frac{A E_{\mathrm{a}}}{R f(\alpha)}\right]-2.315-0.4567 \frac{E_{\mathrm{a}}}{R T_{\mathrm{p}}}
$$

According to the theory that the a values corresponding to each exothermic peak of DSC curve is approximately equal at different heating rates of $\beta$, the value of apparent activation energy $E_{\mathrm{a}}$ can be obtained by fitting the Linear relationship between $\lg \beta$ and $1 / T_{\mathrm{p}}$ as shown in Fig. 5C. The value of slope of the curve was -4140.24 , and the value of $E_{\mathrm{a}}$ was $75.37 \mathrm{~kJ} \mathrm{~mol}^{-1}$. From the above results, the values of apparent activation energy of $E_{\mathrm{a}}$ obtained by the Kissinger and Ozawa equations were

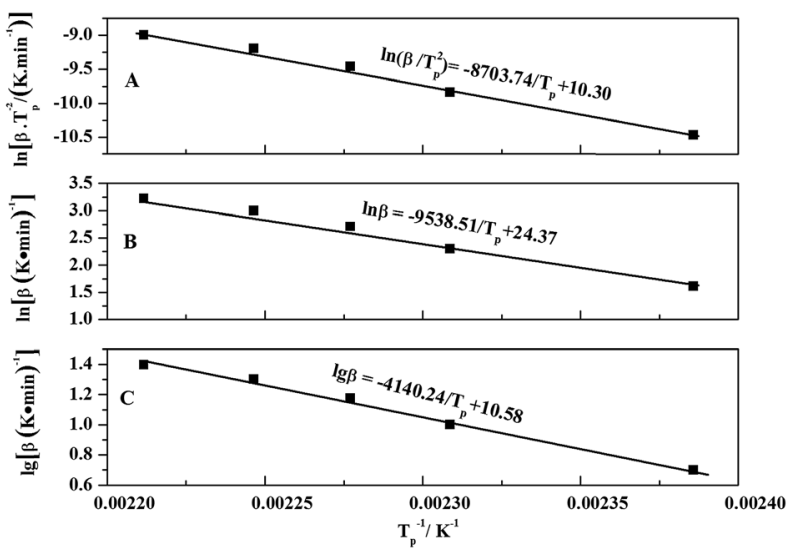

Fig. 5 The relation between $\left(\beta / T_{p}{ }^{2}\right)$ and $1 / T_{p}$ of Kissinger $(A)$, the relation between $\ln \beta /$ and $1 / T_{p}$ of $C$ rnae $(B)$, and the relation between $\lg \beta$ and $1 / T_{\mathrm{p}}$ of Ozawa (C).
Table 3 The kinetics parameters of curing reaction

\begin{tabular}{lcccc}
\hline$\beta /\left(\mathrm{K} \mathrm{min}^{-1}\right)$ & $\ln \left[\beta T_{\mathrm{p}}{ }^{2} /\left(\mathrm{K} \mathrm{min}^{-1}\right]\right.$ & $\ln \beta /\left(\mathrm{K} \mathrm{min}^{-1}\right.$ & $T_{\mathrm{p}}{ }^{-1} / \mathrm{K}^{-1}$ & $A / \mathrm{min}^{-1}$ \\
\hline 5 & -10.467 & 1.609 & 0.00239 & $2.583 \times 10^{8}$ \\
10 & -9.840 & 2.303 & 0.00231 & $2.473 \times 10^{8}$ \\
15 & -9.462 & 2.708 & 0.00228 & $2.742 \times 10^{8}$ \\
20 & -9.201 & 2.996 & 0.00225 & $2.724 \times 10^{8}$ \\
25 & -9.000 & 3.219 & 0.00221 & $2.680 \times 10^{8}$ \\
Average & & & & $2.640 \times 10^{8}$
\end{tabular}

almost equal, which further proved that the kinetic equation of curing reaction process of EP/OBPA/FGE polymer system fitted first order linear relation. The average value of apparent activation energy $E_{\mathrm{a}}$ was $73.87 \mathrm{~kJ} \mathrm{~mol}^{-1}$.

\section{Curing dynamic equation of EP/OBPA/FGE system}

The cure reaction kinetics eqn (10) was obtained via combined eqn (1) and (9), and the eqn (11) came from the integral of eqn (10). The above values of $E_{\mathrm{a}}, A$ and $n$ were brought into the eqn (11), and the kinetic equation of curing reaction process of the EP/OBPA/FGE polymer system was finally obtained in eqn (12). The linear relationship between $\alpha$ and $t$ was obtained in Fig. 6 by means of eqn (11). According to the eqn (11) and Fig. 6, the reaction temperature of EP/OBPA/FGE polymer system was higher, the reaction time was longer, and then the value of conversion rate $\alpha$ was greater.

$$
\begin{gathered}
K=A \exp \left(-E_{\mathrm{a}} / R T_{\mathrm{p}}\right) \\
\frac{\mathrm{d}(\alpha)}{\mathrm{d}(t)}=A \exp \left(-E_{\mathrm{a}} / R T\right)(1-\alpha)^{n} \\
\alpha(t)=1-\left[1+(n-1) A \exp \left(-E_{\mathrm{a}} / R T\right) t\right]^{\frac{1}{1-n}} \\
\alpha(t)=1-\left[1-6.5 \times 10^{4} \exp \left(-8.88 \times 10^{3} / T\right) t\right]^{11.36}
\end{gathered}
$$

where, $K$ represents the rate constant of reaction, $\mathrm{S}^{-1} ; \alpha$ is the reaction progress, $\% ; t$ is the reaction time, $\mathrm{s} ; T$ is the reaction temperature, $\mathrm{K}$.

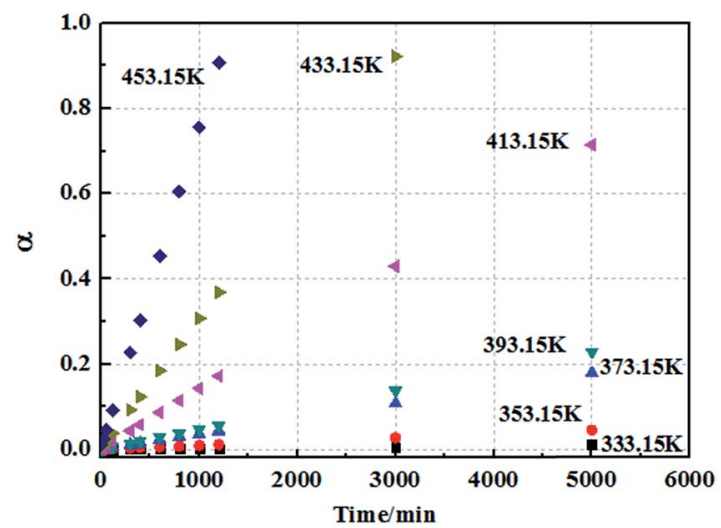

Fig. 6 The relation between $\alpha$ and reaction time of EP/OBPA/FGE system under different temperatures. 


\section{The curing process of EP/OBPA/PGE system}

From the Fig. 1, the curing temperatures of the EP/OBPA/FGE polymer system were different with the increase of the heating rate, and the peak temperatures were different during the whole curing reaction process, and then this makes it difficult to determine the curing temperature of the EP/OBPA/FGE polymer system in the actual curing process. In order to obtain accurate and reliable system characteristic curing temperature, the $T-\beta$ extrapolation method was used to obtain the curing temperature when the heating rate of $\beta$ is $0 \mathrm{Kmin}^{-1}$.

In this work, by recording the characteristic temperature of $T_{\mathrm{i}}, T_{\mathrm{p}}$, and $T_{\mathrm{f}}$ of EP/OBPA/FGE polymer system at different heating rates, then the values of heating rate were used as the horizontal coordinate, and the values of $T_{\mathrm{i}}, T_{\mathrm{p}}$, and $T_{\mathrm{f}}$ were used as the vertical coordinate to get the linear relationship graphs, and the curves were obtained and shown in Fig. 7. The curves were fitted and the following equations were obtained:

$$
\begin{gathered}
T_{\mathrm{i}}=1.32 \beta+336.1, R=0.965 \\
T_{\mathrm{p}}=1.48 \beta+415.1, R=0.935 \\
T_{\mathrm{f}}=13.26 \beta+466.6, R=0.930
\end{gathered}
$$

From the extrapolation of $\beta-T$ results can be known, the peak starting temperature was $336.1 \mathrm{~K}\left(62.95{ }^{\circ} \mathrm{C}\right)$, the peak temperature was $415.1 \mathrm{~K}\left(141.95{ }^{\circ} \mathrm{C}\right)$, and the peak end temperature of was $466.6 \mathrm{~K}\left(193.45{ }^{\circ} \mathrm{C}\right)$ of $\mathrm{EP} / \mathrm{OBPA} / \mathrm{FGE}$ polymer system, respectively. The above temperatures correspond to the gel temperature, curing temperature and post curing temperature of EP/OBPA/FGE polymer system, and the curing conditions of this system was that: firstly, from room temperature to $63{ }^{\circ} \mathrm{C}$ slowly, and then continue to heat up to $142{ }^{\circ} \mathrm{C}$ for constant temperature curing, and finally to heat up to $194{ }^{\circ} \mathrm{C}$ for post curing.

According to the above results, although the parameters of curing temperatures are not established for the system to

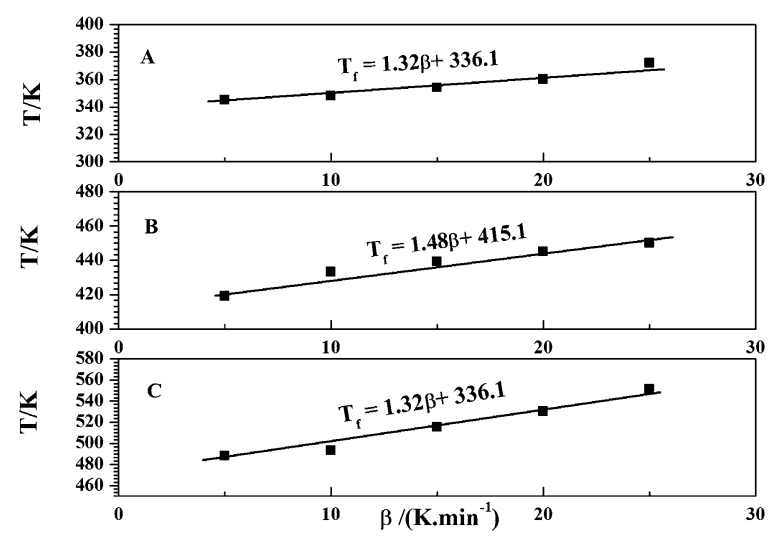

Fig. 7 The extrapolation plots of $\beta-T$. determine the exact curing time, and cannot be directly used as the curing process of the system, it can be a necessary theoretical basis for the formulation of the EP/OBPA/FGE system curing process.

\section{The thermomechanical properties}

In the present work, the curing process of EP/OBPA/FGE system was cured at $80{ }^{\circ} \mathrm{C}$ for $2 \mathrm{~h}$, and then at $150{ }^{\circ} \mathrm{C}$ for $5 \mathrm{~h}$. The glass transition temperature $\left(T_{\mathrm{g}}\right)$ was measured by the NETZSCH DSC 214 instrument under nitrogen and the results of the variation in $T_{\mathrm{g}}$ were listed in Fig. 8. From the Fig. 8, the value of $T_{\mathrm{g}}$ of the system decreased with the increase of diluent FGE, and the value of Tg of EP/OBPA/FGE-0 just is $1.5{ }^{\circ} \mathrm{C}$ higher than the EP/OBPA/FGE-15. Generally speaking, the glass transition temperatures of different systems depend on their own cross-linking density and chain flexible. Compared with stiff phenyl group in the epoxy resin, the conjugated ring in the molecular structure of FGE has high flexibility, while not losing rigidity. As the result, the addition of diluent FGE has little effect on the glass transition temperature of the EP/OBPA system.

\section{The mechanical properties}

The Fig. 9 shows the effect of FGE on the flexural properties and the tensile properties of EP/OBPA systems. From the Fig. 9, the flexural strength of the EP/OBPA systems increased with the increase of FGE, while the tensile strength increases first and then decreases with the increase of the content of reactive diluents of FGE, and reaches its maximum of $72.4 \mathrm{MPa}$ with 10 $\mathrm{wt} \%$ of FGE. It was found that the conjugated ring in the molecular structure of FGE would improve the tenacity of epoxy resin, but when the content of FGE was more than $15 \mathrm{wt} \%$, the tensile strength of EP/OBPA system decreased due to the decrease of cross-linking density. Based on the above results, 10 $\mathrm{wt} \%$ of FGE in the EP/OBPA system possesses better mechanical properties.

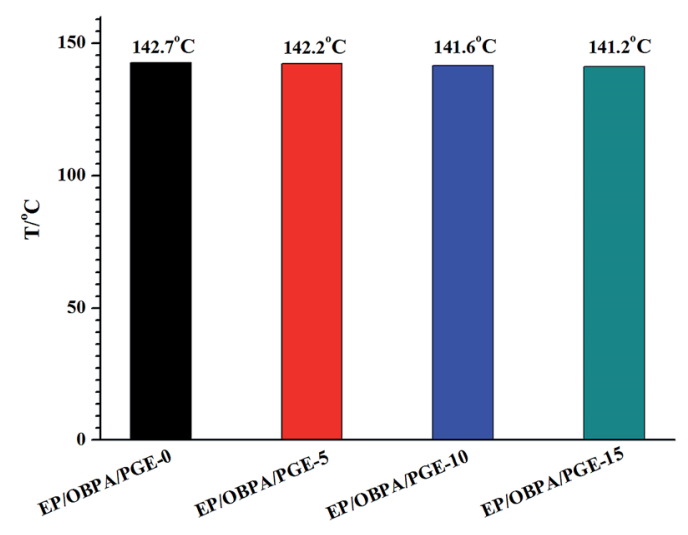

Fig. 8 The glass transition temperature $\left(T_{g}\right)$ : EP/OBPA/FGE- 0 represents the system without any FGE; the EP/OBPA/FGE-5, EP/OBPA/ FGE-10 and EP/OBPA/FGE-15 stand for the systems with FGE in the dosage of $5 \mathrm{wt} \%, 10 \mathrm{wt} \%$ and $15 \mathrm{wt} \%$. 


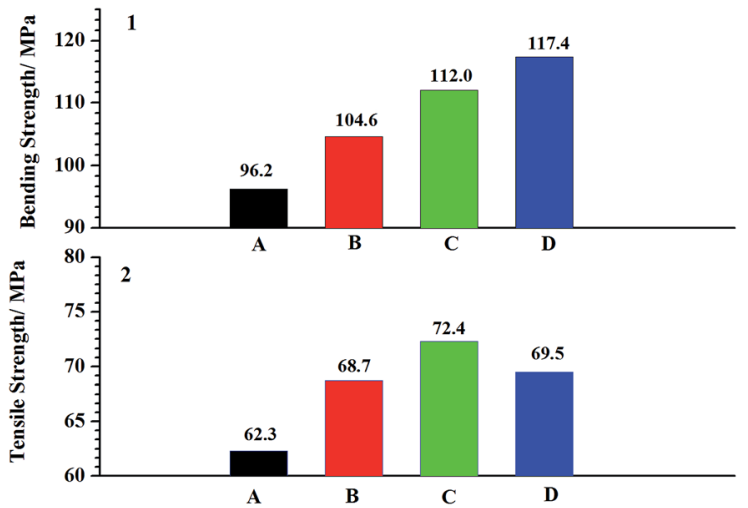

Fig. 9 The mechanical properties: (A) represents the system without any FGE; the $(B-D)$ stand for the systems with FGE in the dosage of 5 $w t \%, 10 w t \%$ and $15 \mathrm{wt} \%$.

\section{Conclusions}

(1) The reactive diluent of FGE and curing agent of OBPA for epoxy resin were synthesized successfully in present work. And their structures were confirmed by FTIR and ${ }^{1} \mathrm{H}$ NMR.

(2) The kinetic equation of curing reaction process of $\mathrm{EP} /$ OBPA/FGE polymer system fitted first order linear relation, the value of pre-exponential factor $A$ was $2.640 \times 10^{8} \mathrm{~min}^{-1}$, and the apparent activation energy $E_{\mathrm{a}}$ was $73.87 \mathrm{~kJ} \mathrm{~mol}^{-1}$.

(3) According to the results of DSC scanning curves and the extrapolation of $T-\beta$ method, the best cure condition of $\mathrm{EP} /$ OBPA/FGE polymer system was that: firstly, it is heated up from room temperature to $63{ }^{\circ} \mathrm{C}$ slowly, and then continued to $142^{\circ} \mathrm{C}$ for constant temperature curing, and finally heated up to $194^{\circ} \mathrm{C}$ for post curing.

(4) The effect of FGE on the thermomechanical properties (glass transition temperature) and mechanical properties (flexural strength and the tensile strength) of EP/OBPA/FGE were studied, and EP/OBPA/FGE-10 (with $10 \mathrm{wt} \%$ of FGE) has the best mechanical properties.

\section{Acknowledgements}

The research is financially supported by the National Natural Science Foundation of China (Grant no. 21404112), China Postdoctoral Science Foundation (Grant no. 2014M561798) and Ningbo Natural Science Foundation (Grant no. 2015A610016).

\section{Notes and references}

1 Y. L. Liu and C. Y. Hsieh, J. Polym. Sci., Part A: Polym. Chem., 2006, 44, 905.
2 Y. L. Liu, C. Y. Hsieh and Y. W. Chen, Polymer, 2006, 47, 2581.

3 T. Qiao, Z. R. Min, Q. Z. Ming and C. Y. Yan, Polym. Int., 2010, 59, 1339.

4 Y. C. Yuan, T. Yin, M. Z. Rong and M. Q. Zhang, eXPRESS Polym. Lett., 2008, 2, 238.

5 Y. C. Yuan, M. Z. Rong, M. Q. Zhang, J. Chen, G. C. Yang and X. M. Li, Macromolecules, 2008, 41, 5197.

6 E. B. Murphy, E. Bolanos, C. Schaffner-Hamann, F. Wudl, S. R. Nutt and M. L. Auad, Macromolecules, 2008, 41, 3169.

7 D. S. Xiao, Y. C. Yuan, M. Z. Rong and M. Q. Zhang, Adv. Funct. Mater., 2009, 19, 2289.

8 M. R. Ghodsieh, K. M. Amar and M. Manjusri, ACS Sustainable Chem. Eng., 2014, 2, 2111.

9 J. Qin, M. Woloctt and J. Zhang, ACS Sustainable Chem. Eng., 2014, 2, 188.

10 F. Ferdosian, M. Ebrahimi and A. Jannesari, Thermochim. Acta, 2013, 568, 67.

11 J. Wang, H. Wang, J. Liu, W. Liu and X. Shen, J. Therm. Anal. Calorim., 2013, 114, 1255.

12 R. Hardis, J. Jessop and M. R. Kessler, Composites, Part A, 2013, 49, 100.

13 P. P. Adroja, R. Y. Ghumara and P. H. Parsania, J. Appl. Polym. Sci., 2013, 130, 572.

14 F. S. Hu, J. J. La Scala, J. M. Sadler and G. P. Palmese, Macromolecules, 2014, 47, 3332.

15 W. Huang, X. Q. Liu, J. Zhu and Q. Y. Cao, Chemistry, 2011, 74, 92.

16 S. Q. Ma, X. Q. Liu, Y. H. Jiang, Z. B. Tang, C. Z. Zhang and J. Zhu, Green Chem., 2013, 15, 245.

17 N. El-Thaher, P. Mussone, D. Bressler and P. Choi, ACS Sustainable Chem. Eng., 2014, 2, 282.

18 F. Jaillet, M. Desroches, R. Auvergne, B. Boutevin and S. Caillol, Eur. J. Lipid Sci. Technol., 2013, 115, 698.

19 R. Wang, T. Schuman, R. R. Vuppalapati and K. Chandrashekhara, Green Chem., 2014, 16, 1871.

20 J. W. Song, R. Guo, J. B. Liu and B. T. Wang, Appl. Chem. Ind., 2015, 44, 559.

21 L. W. Crane, J. Polym. Sci., Polym. Lett. Ed., 1973, 11, 533. 22 L. F. Zhao, Y. Liu and Z. D. Xu, For. Stud. China, 2011, 13, 21. 23 S. Kim and H. J. Kim, Int. J. Adhes. Adhes., 2005, 18, 456.

24 B. A. Gustavo, G. P. Leonardo, S. A. André, C. F. Ronaldo, A. P. Marcelo, C. M. Paulo and A. G. Maria, Chem. Phys., 2011, 13, 21233.

25 J. Y. Zhang, S. J. Chen, Z. Y. Zhu and S. Y. Liu, Chem. Phys., 2014, 16, 117. 